\title{
The Electrochemical Performance of Ferrosilicon Master Alloy as Anode Material for Lithium-Ion Batteries
}

\author{
Lin Wu, Xinlin Zhang, Liwu Huang* ${ }^{*}$ Yungui Chen ${ }^{*}$ \\ College of Materials Science and Engineering, Sichuan University, Chengdu 610065, PR China \\ *E-mail: liwuhuang@scu.edu.cn, ygchen60@aliyun.com
}

doi: $10.20964 / 2019.06 .69$

Received: 16 February 2019 / Accepted: 9 April 2019 / Published: 10 May 2019

\begin{abstract}
Alloy electrode has greatly improved the low $\mathrm{Li}^{+} /$electron conductivity and relieved the huge volume expansion of Si via using elastic inactive matrix to accommodate the active component. Here we choose ferrosilicon master alloy (FS) used widely in the metallurgical industry as possible negative electrode materials with $\mathrm{Si}$ as active center and highly conductive FeSi phase as elastic matrix. The carbon coating ferrosilicon (FSC) anode exhibits a good cycle performance of $430 \mathrm{mAh} \mathrm{g}^{-1}$ after 100 cycles and a good rate performance of $400 \mathrm{mAh} \mathrm{g}^{-1}$ at a current density of $1000 \mathrm{~mA} \mathrm{~g}^{-1}$. To confirm the charge/discharge reaction mechanism, XRD was applied to detect the phase changes of the anode during the first three reaction processes. It can be seen from the results that the amorphous carbon layer and FeSi phase can act as a buffer layer to relax the stress of Si and improve the electrical conductivity among Si particles during cycling.
\end{abstract}

Keywords: ferrosilicon; lithium-ion batteries; reaction mechanism; anode

\section{FULL TEXT}

(C) 2019 The Authors. Published by ESG (www.electrochemsci.org). This article is an open access article distributed under the terms and conditions of the Creative Commons Attribution license (http://creativecommons.org/licenses/by/4.0/). 